\title{
UV-radiation Dose Assessment for Lexan Track Detector by Using of UV-visible and FTIR Spectroscopy Techniques
}

\author{
Hussain A. Al-Jobouri and Fala Hatem Taha \\ Department of Physics, College of Science, Al-Nahrain University, Baghdad-Iraq.
}

\begin{abstract}
In the present work, studies the effect UV-radiation dose $\left(1 \mathrm{~J} / \mathrm{cm}^{2}-360 \mathrm{~J} / \mathrm{cm}^{2}\right)$ with power $15 \mathrm{~W}$ to Lexan track detector thickness $175 \mu \mathrm{m}$. Absorbance $-\mathrm{A}$ was measured at wavelength $300 \mathrm{~nm}$ and $305 \mathrm{~nm}$ by using UV-visiblespectroscopy and measure the transmission percent-T\% and deviation at the wave number-w $940 \mathrm{~cm}^{-1}$ by using Fourier infrared -FTIR spectroscopy. The relationship between the radiation dose of the UV-radiation $\left(\mathrm{J} / \mathrm{cm}^{2}\right)$ and the absorbance-Aat wavelength $300 \mathrm{~nm}$ and $305 \mathrm{~nm}$ and the wave number-w $940 \mathrm{~cm}^{-1}$ was calculate as a polynomial relation. The present study show that there is a possibility to use the detector Lexan to assessment doses of exposure to UV-radiation in the medical and environmental fields .
\end{abstract}

Keywords: Track Detector; Lexan; UV; UV-visible; FTIR.

\section{Introduction}

Lexan polycarbonate its chemical structure $\mathrm{C}_{16} \mathrm{H}_{14} \mathrm{O}_{3}$ is shown in Fig.(1) is a promising polymer having high transparency in the visible spectrum range, which is used in all fields of life viz. optical[1], medical, electronic, space applications and for recording ion tracks [2] where its low weight, chemical inertness, high impact resistance and relatively low cost are of major importance. During the last few decades, some materials like metals and ceramics have been replaced by polymers because of their superior advantages. However, some features of polymers should be modified ionizing radiation, laser or UV-radiation [3] could be used for this purpose.

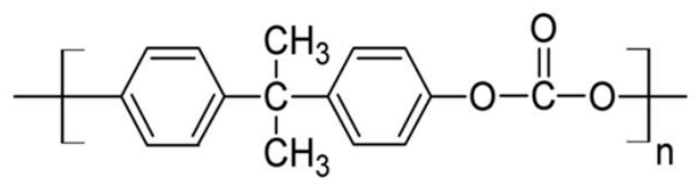

Fig.(1) Chemical structure for Lexan [1].

The changes induced in the polymer by UV-radiation depend on the time of exposure and also on the wavelength of UV-radiation. In case of short wavelength UV-irradiation, the energy is sufficient enough to break polymer bonds leading to scission of the polymer chains. In addition, depending upon the polymer structure, the free radicals generated may combine with other radicals resulting in cross-linking. UV-irradiation effects on polyallyldiglycol carbonate-PADC detector have been studied by Tse et.al, [4]. Dwaikat et.al, [5] studied the effects of UV-laser lightat $\lambda$ : 266 nmand incoherent UV- radiation at $\lambda: 254 \mathrm{~nm}$ onthe properties of CR-39 polymer. The mechanical and surface morphological changes of PMMA by UV-radiation have been studied by Eve and Mohr [6].

The radiation induced changes of the properties of polymer are very specific with respect to the type of polymer, radiation and its environment. The polymers which are difficult to process by chemical methods can be easily modified using UV or gamma radiation [7]. This leads to changes in structural [8], thermal, optical and surface morphological properties [9] due to radiochemical alterations such as unsaturation, evolution of gases, creation of defects, amorphization, etc. As a result, irradiation of polymers his shown great potentialin many fields such as microelectronics, biomedical, device technology nano-materials and materials science [10]. Literature survey indicates that the effects of gamma radiation on Lexan polycarbonate are being extensively studied [11]. It was further observed that there was a substantial chemical and thermal modification in the Lexan polycarbonate sample, such as breaking of $\mathrm{C}-\mathrm{O}$ single bond and formation of phenolic bond and gradual decrease in the glass transition temperature, with the increase in ion fluence of $100 \mathrm{MeV}$ silicon ions [12]. 
As per literature survey, until now, no study has been carried out on the characterization of structural, optical and mechanical modifications of UV-irradiated Lexan polycarbonate. Therefore, in the present investigation, an attempt has been made to study the effect of UV-radiation on the abovementioned properties of Lexan polycarbonate using x-ray diffraction, Fourier transform infrared-FTIR spectroscopy, scanning electron microscope-SEM, differential scanning calorimetry-DSC, UV-visible spectroscopy, impedance analysis, tensile testing and rheometry analyses. An attempt was also made to correlate the results with reported data to make the present work more informative from a scientific point of view [13]. Lexan detector was used to assessment UV-irradiation dose by using UV-visible and FTIR spectroscopy technique.

\section{Experimental Procedure}

Lexan nuclear track detector, sheets is (the factory of the company Co. Chan Zhou Weldin) with thickness $175 \mu \mathrm{m}$, were cut into small pieces of $2 \mathrm{~cm} \times 2 \mathrm{~cm}$. The source of UV-radiation was model FLUO-LINK FLX system from transilluminator with wavelength $254 \mathrm{~nm}$ and $15 \mathrm{~W}$ the power.

The distance between source of UVirradiation and samples was $4 \mathrm{~cm}$, UVirradiation doses were 1,5,30,60,120,240 and $360 \mathrm{~J} / \mathrm{cm}^{2}, \mathrm{UV}$-irradiation for all samples was carried out in air and at room temperature.

\section{Results and Discussion}

\section{1. $U V$-visible spectroscopy analysis}

Fig.(2) shows the increase in absorbance-A of the Lexan samples which measured by UV-visible technique at the range $290-330 \mathrm{~nm}$ to the samples of Lexan with increase irradiation dose of UV-radiation at the range $10,60,120,240$ and $360 \mathrm{~J} / \mathrm{cm}^{2}$ compared with un-irradiated sample. This figure shows the increase in absorbance-A with increase of radiation dose. The maximum in absorbance- $A$ with irradiation dose were appear at the wavelengths $300 \mathrm{~nm}, 305 \mathrm{~nm}$ as shown in Fig. (3) and Fig. (4) respectively.

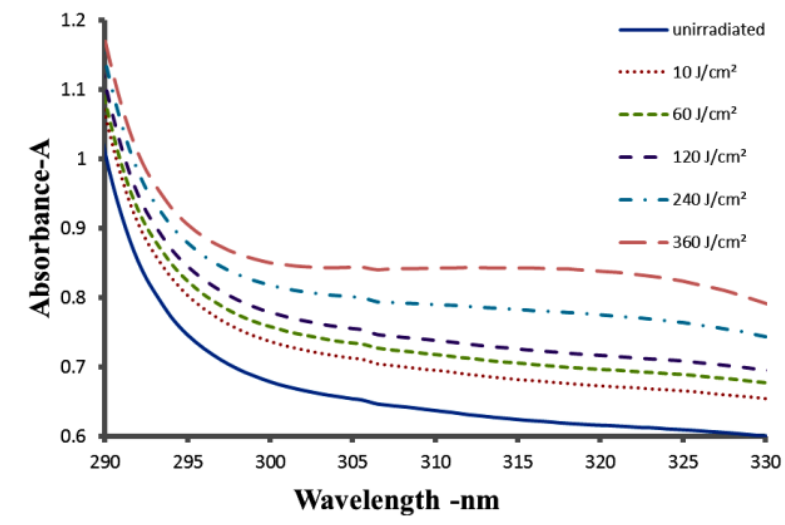

Fig.(2) Absorbance-A by $U V$-visible spectroscopy technique with

Wavelength range $(290-330 \mathrm{~nm})$ for un-irradiated and $U V$-irradiated at dose range of 10,60,120,240, and $360 \mathrm{~J} / \mathrm{cm}^{2}$ for Lexan detector.

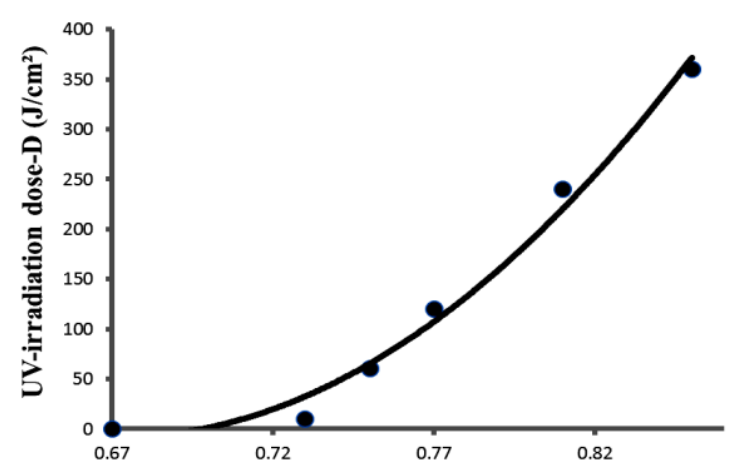

Absorbance-A

Fig.(3) Absorbance-A vs. UV-irradiation dose-D $\left(\mathrm{J} / \mathrm{cm}^{2}\right)$ for Lexan detector at wavelength $300 \mathrm{~nm}$.

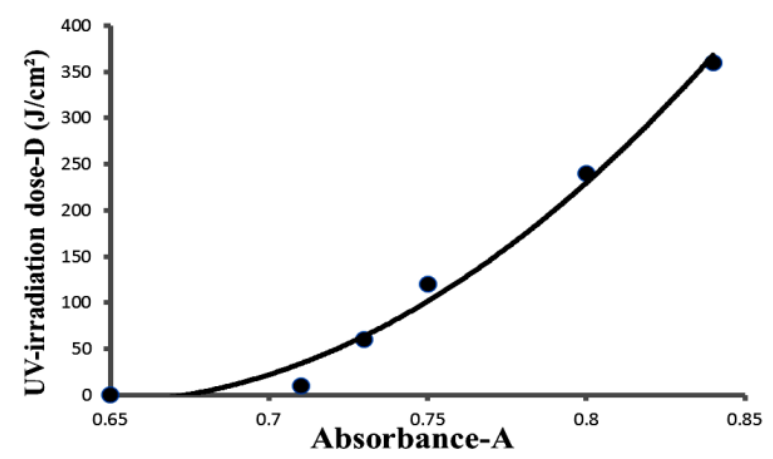

Fig. (4) Absorbance-A vs. $U V$-irradiation dose-D $\left(J / \mathrm{cm}^{2}\right)$ for Lexan detector at wavelength $305 \mathrm{~nm}$.

Fig. (3) and Fig. (4) shown the polynomial relationship between the absorbance-A and UV-irradiation dose at 300 nmand $305 \mathrm{~nm}$ respectively. Which are described equation (1) and equation (2). 
$D\left(\mathrm{~J} / \mathrm{cm}^{2}\right)=1 \times 10^{4} \mathrm{~A}^{2}-1 \times 10^{4} \mathrm{~A}+5.7 \times 10^{3}$

$D\left(J / \mathrm{cm}^{2}\right)=9.2 \times 10^{3} \mathrm{~A}^{2}-1 \times 10^{4} \mathrm{~A}+4.7 \times 10^{3}$

where $\mathrm{D}\left(\mathrm{J} / \mathrm{cm}^{2}\right)$ : UV- irradiation dose, $\mathrm{A}$ : Absorbance

The maximum response of UV-radiation dose $360 \mathrm{~J} / \mathrm{cm}^{2}$ at wavelength $305 \mathrm{~nm}$ was calculated at absorbance-A value 0.84 as shown in Fig. (4). The change in absorbance-A at 300-305 nm was also happen when determine comparison between solar UV-simulator and overhead sun for CR-39 [14]. And this change in absorbance-A at $305 \mathrm{~nm}$ was happen as result of attributed to the formation of conjugated system of bonds due to bond cleavage and reconstruction supporting the structural and chemical modification in PC (Lexan) after irradiation [13].

\section{FTIR-spectroscopy analysis}

FTIR-spectrum in Fig.(5) shows the change that appears in transmission percent-T\% which measured by FTIRspectroscopy technique at wavenumber range 400-3800 $\mathrm{cm}^{-1}$ to the samples of Lexan which irradiated by UV- radiation at range1,5,10,60,120, 240 and $360 \mathrm{~J} / \mathrm{cm}^{2}$ compared with un-irradiated sample. The change in the shape of FTIR-spectrum with irradiation dose $\left(\mathrm{J} / \mathrm{cm}^{2}\right)$ appear in wavenumber-w $940 \mathrm{~cm}^{-1}$ as shown in Fig.(6).

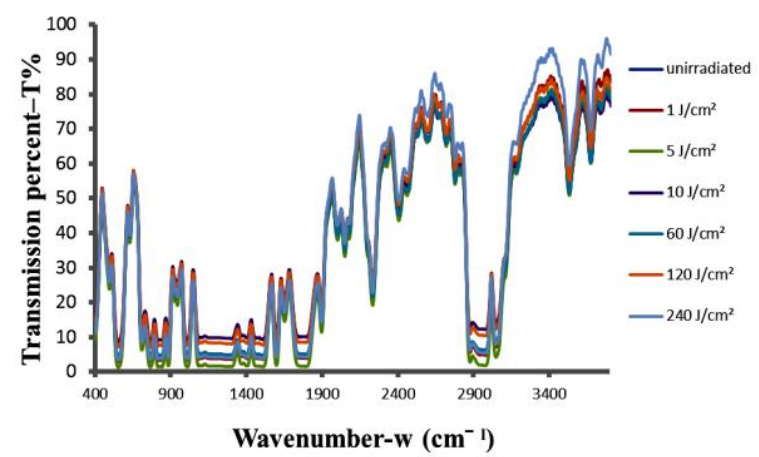

Fig.(5) Transmission percent -T\% with wavenumber-w $\left(\mathrm{cm}^{-1}\right)$ from FTIRspectroscopy technique for un-irradiated and $U V$-irradiated at dose range $1,5,10,60,120,240$ and $360 \mathrm{~J} / \mathrm{cm}^{2}$ for Lexan detector.

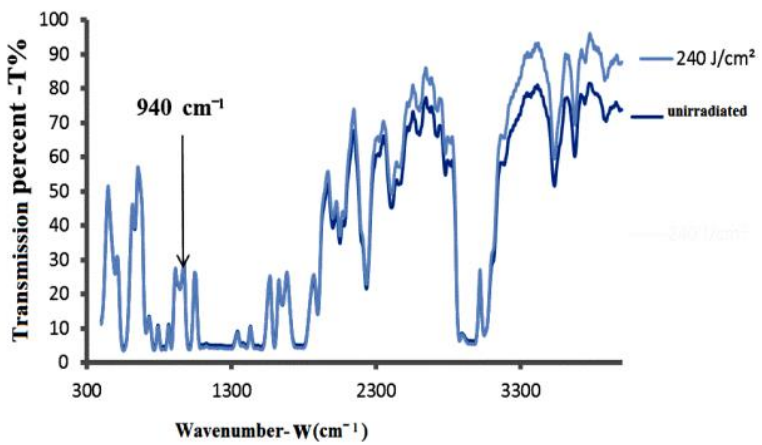

Fig.(6) Transmission percent-T\% with wavenumber-w $\left(\mathrm{cm}^{-1}\right)$ by FTIR spectroscopy technique for un-irradiated and $U V$-irradiated at dose $240 \mathrm{~J} / \mathrm{cm}^{2}$ for Lexan detector.

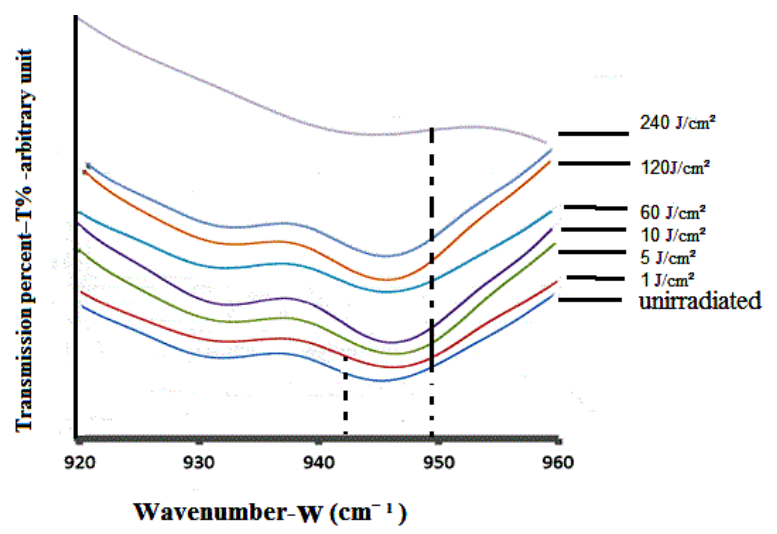

Fig.(7) Deviation of FTIR-spectrum at wavenumber- $w 940 \mathrm{~cm}^{-1}$ for $u v$-irradiation and $\boldsymbol{U V}$-irradiated Lexan detector at dose range $1 \mathrm{~J} / \mathrm{cm}^{2}$ to $240 \mathrm{~J} / \mathrm{cm}^{2}$.

Fig. (7) shows the change in deviation of wavenumber-w value $940 \mathrm{~cm}^{-1}$ with irradiation dose from $1 \mathrm{~J} / \mathrm{cm}^{2}$ to $240 \mathrm{~J} / \mathrm{cm}^{2}$. And this deviation may be as a result formation of phenoxy radical and phenyl radical [13].

Fig. (8) shows the polynomial relationship between the UV-irradiation dose and the deviation in wavenumber-w at940 $\mathrm{cm}^{-1}$ and the UV-radiation dose from above dose range.

These behavior of determine between radiation dose and wavenumber-w by following equation.

$D\left(\mathrm{~J} / \mathrm{cm}^{2}\right)=1.9 w^{4}-7.8 \times 10^{3} w^{3}+1 \times 10^{7} w^{2}-$

$7 \times 10^{9} w+2 \times 10^{12}$

where D $\left(\mathrm{J} / \mathrm{cm}^{2}\right)$ : UV- irradiation dose, w: wavenumber $\mathrm{cm}^{-1}$. 


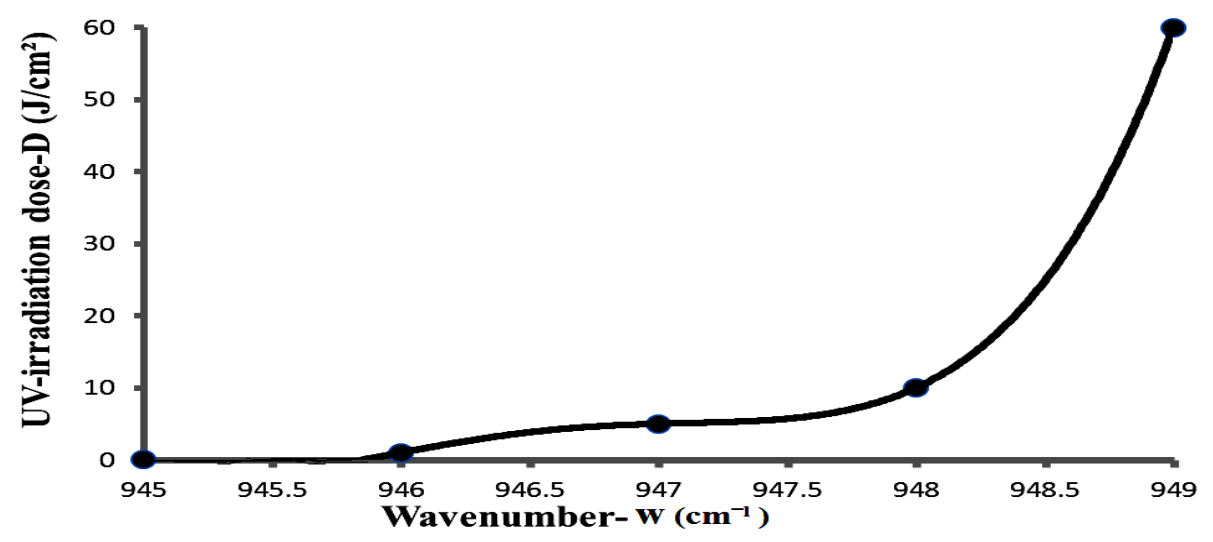

Fig.(8) Behavior of FTIR-spectrum deviation at wavenumber-w $940 \mathrm{~cm}^{-1}$ for Lexan vs. $U V$-irradiation dose range from $1 \mathrm{~J} / \mathrm{cm}^{2}$ to $240 \mathrm{~J} / \mathrm{cm}^{2}$.

Table (1)

Equations of $U V$-radiation doseassessment for Lexan detector by measuring of wavelength at $300 \mathrm{~nm}, 304 \mathrm{~nm}$ and wavenumber-w at $940 \mathrm{~cm}^{-1}$ by using of $U V$-visible and FTIR spectroscopytechniques respectively.

\begin{tabular}{|c|c|c|c|c|}
\hline Technique & Equations & NO. & & \\
\hline 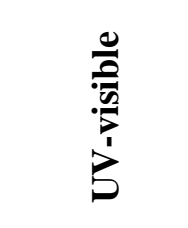 & $\begin{array}{l}D\left(J / \mathrm{cm}^{2}\right)=1 \times 10^{4} A^{2}-1 \times 10^{4} A+5.7 \times 10^{3} \\
D\left(J / \mathrm{cm}^{2}\right)=9.2 \times 10^{3} A^{2}-1 \times 10^{4} A+4.7 \times 10^{3}\end{array}$ & $\begin{array}{l}1 \\
2\end{array}$ & $\begin{array}{l}300 \\
305\end{array}$ & 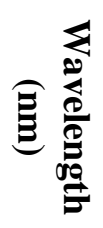 \\
\hline 苯 & $\begin{array}{c}D\left(J / \mathrm{cm}^{2}\right)=1.9 w^{4}-7.8 \times 10^{3} w^{3}+1 \times 10^{7} w^{2} \\
-7 \times 10^{9} w+2 \times 10^{12}\end{array}$ & 3 & 940 & 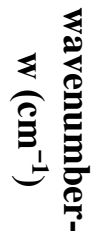 \\
\hline
\end{tabular}

Table (1) represents equation of UV-radiation by measuring of wavelength at $300 \mathrm{~nm}, 304 \mathrm{~nm}$ and wave number-w at $940 \mathrm{~cm}^{-1}$ by using of UV-visible and FTIR spectroscopy respectively technique. From this Table may be use content the UV-radiation dose $\left(\mathrm{J} / \mathrm{cm}^{2}\right)$ by uses Equation (1) and Equation (2) after measuring the wavelength at $300 \mathrm{~nm}$ and $305 \mathrm{~nm}$ respectively. Also, content the UV-radiation dose $\left(\mathrm{J} / \mathrm{cm}^{2}\right)$ by uses Equation(3) after measuring the wave number-w at $940 \mathrm{~cm}^{-}{ }^{1}$. This study also used from determined the UV-radiation dose for the medical and environmental fields

\section{Reference}

[1] Anthony BT "Lexan polycarbonate for automotive forward lighting". Mater Des 6:293-302, (1985).

[2] Raj Prakash HG, Sanjeev G, Vijay Kumar KB, Siddappa K, Nayak BK, Saxena A "Experimental determination of photofission cross-section of 232 Th using electron accelerator". Ann Nucl Energy 38: 757-766, (2011).

[3] Banisadr S, Asempour H "Effect of ferric salt of orange peel solid fraction on photooxidation and biodegradability of LDPE films". Iran Polym J 21:463-471, (2012).

[4] Tse KCC, Ng FMF, Yu KN "Photodegradation of PADC by UV radiation at various wavelengths". Polym Degrad Stab2388_91:2380,(2006). 
[5] Dwaikat N, Sato F, Kato Y, Iida T "The effect of twoultraviolet sources on the etching properties of a solid-statenuclear track detector CR-39”. NuclInst Meth Phys Res A 584:353-357, (2008).

[6] Eve S, Mohr J "Study of the surface modification of the PMMA by UVradiation". Proc Eng 1:237-240, (2009).

[7] Sangappa Demappa T, Mahadevaiah Ganesha S, Divakara S, Pattabi M, Somashekar R "Physical and thermal properties of $8 \mathrm{MeV}$ electron beam irradiated HPMC polymer films". NuclInstrum Methods Phys Res B 266:3975-3980, (2008).

[8] Ramola RC, Chandra S, Negi A, Rana JMS, Annapoorni S, Sonkawade RG, Kulriya PK, Srivastava "AStudy of optical bandgap, carbonaceous clusters and structuring in CR-39 and PET polymers irradiated by $100 \mathrm{MeV} \mathrm{O}^{+7}$ ions". Phys B 404:26-30, (2009).

[9] Ramola RC, Chandra S, Rana JMS, Sonkawade RG, Kulriya PK, Fouran S, Avasthi DK, Annapoorni S “A comparative study of the effect of $\mathrm{O}^{+7}$ ion beam on polypyrrole and CR-39 (DOP) polymers". J Phys D Appl Phys 41:115411(1-6),(2008).

[10] Jagielski J, Turos A, Bielinski D, AbdulKader AM, Piatkowska A "Ion-beam modified polymers for biomedical applications". NuclInstrum Methods Phys Res B 261:690-693, (2007).

[11] Sharma T, Aggarwal S, Sharma A, Kumar S, Mittal VK, Kalsi PC, "Manchanda VK Modification of optical properties of polycarbonate by gamma irradiation". Radiat Eff Defects Solids 163:161- 167, (2008).

[12] Srivastava A, Singh TV, Mule S, Rajan CR, Ponrathnam S. "Study of chemical, optical and thermal modifications induced by $100 \mathrm{MeV}$ silicon ions ina polycarbonate film". NuclInstrum Methods Phys Res B 192:402-406, (2002).

[13] K. Hareesh, Ganesh Sanjeev, A. K. Pandey, Vijayalakshmi Rao. "Characterization of UV- irradiated Lexan polycarbonate films", (Iran Polym J 22(5):341-349, (2013).
[14] R. Shweikani*, G. Raja, A.A. Sawaf, "The possibility of using plastic detectors CR-39 as UV dosimeters", Radiation Measurements 35, 281-285, (2002).

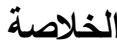

في هذا العمل نم دراسة تأثير الأشعة الفوق البنفسجية على الكانف Lexan الذي سمكه 175 عند مدى الجرع من J/cm² 1 الىى J/cm² 360 بطاقة 15ونم قياس الامتصاصية الضوئية A-باستخدام مطيافية الضوء المرئي UV-visible تحول فورير تحت الحمراء-FTIR.وتم استخراج العلاقة بين الجرعة الاشعاعية UV بوحدة (J/cm²) وبين الامتصاصية الضوئية A- عند الطول الموجي 300nm و 305 وبين

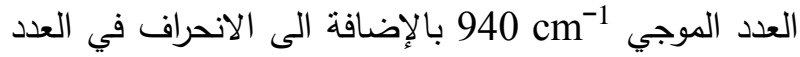

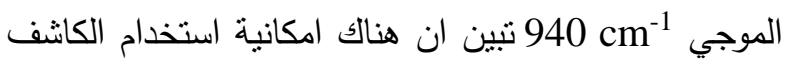

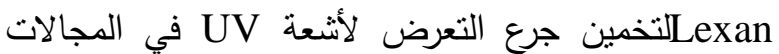
الطبية والبيئية. 